\title{
AQUISIÇÕES RECENTES SOBRE A INSULINA
}

\author{
Conferência realizada no curso "As concepções actuais da En- \\ docrinologia" patrocinada pelo Dep. Científico do C. A. O. C.
}

PROF. DR. KARL SLOTTA

Ex-Chefe da Universidade de Breslau,

Ex-Chefe da Seç̧ão de Química do Instituto Butantã

Neste ano, perdeu a vida em um acidente de avião, quando viajava do Canadá para a Inglaterra, o cientista BAnting, que com BEST e CoLLIP, preparou há anos pela primeira vez, a insulina (1), salvando assim, a vida de milhares de diabéticos. Entretanto, a insulina não representava apenas um novo medicamento, que viria enriquecer os recursos da medicina prática. Sua descoberta tem uma significação muito maior. Constituiu com efeito, um progresso decisivo da bio-química e da endocrinologia. A insulina foi o primeiro hormônio de estrutura proteica, que se obteve em estado de relativa pureza e se poude dosar biologicamente com exatidão. Quís o destino em 1921, entregar nas mãos dos hormonologistas, 'a insulina, o mais simples dos hormônios proteicos. Cumpre meditar sobre a importância deste conhecimento, no âmbito da hormonologia.

Fixemos a definição clássica de hormônio: Hormônios são produtos de glândulas endo-secretoras, lançados em quantidades mínimas na corrente circulatória desenvolvendo ações fisiológicas à distância do seu ponto de produção. Vejamos mais, quais as glândulas endócrinas, que de qualquer forma nos possam interessar como produtoras de hormônios. Sem dúvida, estamos hoje mais instruidos sobre a natureza dos hormônios das glândulas sexuais e das suprarrenais. Em 1929, Dorsy descobriu a estrona ${ }^{(2)}$, em 1934, eu a progesterona ${ }^{(3)}$, em 1935, LAQUeUR a testosterona. (4) e em 1.937, REICHSTEIN a corticosterona (5). Todos estes hormônios pertencem quimicamente, à mesma classe de substâncias. São corpos com o mesmo esqueleto, igual ao da colesterina e dos ácidos biliares.

Muito antes, em 1904, Stolz descobrira o hormônió da medula das glândulas suprarrenais, a adrenalina ${ }^{(6)}$, que representa uma 'substância quimicamente ainda mais simples do que os hormônios sexuais. A-cerca-dos hormônios da glândula pineal, das paratireóides e do timo, quasi nada sabemos.

Da tireóide, só sabemos ao certo que a tiroxina, obtida em 1926 por Harington (7) da glândula, cristalizada e depois esclarecida e sintetizada, não representa o hormônio propriamente dito. Como o hormônio genuino, devemos considerar uma molécula proteica, na 
qual se acha incluida a tiroxina ${ }^{(8)}$. Aquí aparece então ưm problema mais complexo, qual seja um hormônio proteico, cujo mistério químico é de solução dificílima. Realmentẹ, são muito superficiais os nossos conhecimentós relativos à éstrutura das proteinas as mais simples, de que dispomos às toneladas, como caseina, gelatina, hemoglobina, ovo-albumina, fibrina da seda, etc.. Cientistas aos milhares, teem se dedicado a assunto, porem, o progresso foi pequeno.

Quão dificil portanto, deve ser descobrir a constituição dos hormônios proteicos da tireóide, do pâncreas e da hipófise! Destas substâncias se dispõe apenas de algumas gramas, de um valor extraordinário. Com os nossos conhecimentos e recursos de hoje é extremamente dificil o desvendamento dos hormônios proteicos da hipófise. Esta pequenina glândula, constituida por três espécies de células, produz de 12 a 24 hormônios, que atuam sobre todas as demais glândulas do corpo, como tambem sobre o crescimento, o metabolismo, a pressão sanguínea, a diurese e a musculatura lisa. Talvez uma das moléculas proteicas formadas na hipófise possua diferentes ąções fisiológicas; talvez pequeníssimas transformações químicas, modifiquem a atividade do mesmo hormônio hipofisário. $\mathrm{O}$ assunto é ainda um tanto obscuro. Certo é que não temos em mãos - talvez com uma exceção - nenhum dos muitos hormônios da hipófise em forma aproximadamente pura.

Esta é a razão porque - dizìa eu - a descoberta da insulina em 1921, nos pareceu tão bemvinda, mesmo abstraindo de sua importậncia médico-prática. $\mathrm{Na}$ insulina, temos uma molécula proteica relativamente simples, dotada de uma ação fisiológica nitidamente circunscrita sobre o metabolismo do açucar. Podemos provar esta ação em animais de laboratório, de preferência no coelho, com muito rigor e de modo relativamente simples, por meio de determinaçôes da glicemia. Deixa-se jejuar coelhos com $2 \mathrm{~kg}$ de peso durante 24 horas, determina-se sua glicemia, injeta-se o preparado de insulina e torna-se a medir a glicenia no fim de 5 horas. Chama-se unidade internacional a terça parte da quantidade de insulina, que abaixa de $45 \mathrm{mg} \%$ nivel glicêmico. O preparado-padrão internacional contem 22 dessas unidades em $1 \mathrm{mg}{ }^{\left({ }^{9}\right)}$. E natural que, para determinar um preparado de insulina completamente desconhecido são necessárias 250 a 500 determinações de glicemia. Mas isto, comparado com as determinações de muitos outros hormônios, é relativamente facil. Principalmente porque não existe, na mesma glândula, dezenas de hormônios semelhantes e sensíveis, como ocorre na hipófise. $\mathrm{Na}$ glândula pancreática temos um hormônio proteico, dotado de uma ação facilmente determinavel.

A segunda grande vantagem que o hormônio pancreático oferece à pesquisa, é ser facilmente obtido e relativamente insensivel. O pâncreas é grande e constituido por $1 / 10.000$ de insulina (10). A hipófise é extraordinariamente pequena, e eu duvido que ela contenha 
qualquer um dos seus hormônios $\mathrm{em}$ proporção relativamente tão alta. A insulina é muito mais duravel que os outros hormônios proteicos. Em solução ácida, é de conservação quasi ilimitada (11).

A terceira vantagem, oferecida aos pesquisadores de insulina, frente àqueles que trabalham no desvendamento de outros hormônios proteicos, é ser a insulina muito pequena. A respeito, devo esclarecer dois pontós. Por ora, só falo da insulina, como a conheciamos há 20 anos. . Quando um estudante completa 20 anos, ninguem o chama de velho. A Ansulina andou mais depressa - já aos 18 anos foi chamada "insulina velha" ("Alt-insulin"). Verificou-se que a insulina, tal como a empregamos, era apenas uma fração do hormônio produzido pelo pâncreas. "Fala-se agora de "insulina-nativa" na qual a "insulina-velha" estaria apenas incluida Se porem, abstrairmos disso, a molécula da "insulina velha", é relativamente, pequena.

O têrmo "relativamente" é o segundo ponto que desejo esclarecer. Desde que um átomo de hidrogênio tem o peso de 1 , uma molécula de alcool pesa 46 vezes mais, os hormônios sexuais e as vitaminas muito mais complexos teem um peso molecular de aproximadamente 400. Ora, sabemos todos que já procuramos guardar de memória as fórmulas estruturais da testosterona ou da vitamina $D$, que as substâncias orgânicas, com tais pesos, moleculares, são formações bastante complexas. São entretanto, extremamente pequenas em comparação com os pesos moleculares das proteinas.

As menores moléculas de proteina teem pesos moleculares por volta de 17.600; mas são poucas. Muitas são duas ou quatro vezes mais pesadas, e as interessantíssimas moléculas de virus são mil vezes mais pesadas. Digno de nota é ainda o fato de existirem sempre grupos de espécies proteicas com pesos moleculares semelhantes, e estes previlegiados pesos moleculares geralmente são múltiplos de $17.600^{(12)}$. (Fig. 1)

Affim de tornar estes valores relativamente objetivos, desenhei, sob forma de círculos, uma vitamina, cujo peso molecular é cerca de 400, a molécula proteica relativamente pequena da insulina e uma molécula enorme tal como um virus. As superfícies destes círculos são proporcionais aos pesos moleculares. A insulina possue portanto, como todas as moléculas proteicas, um peso molecular muito elevado em comparação com as moléculas orgânicas ordinárias, mas muito reduzido em relação a muitas outras substâncias proteicas ${ }^{(13)}$. (Fig. 2)

Devido pois, à sua dẹterminação fisiológica relativamente facil, sua acessibilidade relativamente cômoda, sua durabilidade relativamente grande e o seu peso molecular relativamente pequeno, a insulina é o hormônio próteico ideal para o pesquisador. Ela serviu de campo de experimentação durante vinte anos.

Vejamos o que resultou destes trabalhos. O primeiro grande progresso fồ quando ABEL em 1925 consegưiu obter insulina cristalizada ${ }^{(14)}$. Utilizava uma insulina bastante pura contendo $13 \mathrm{U}$. I. 


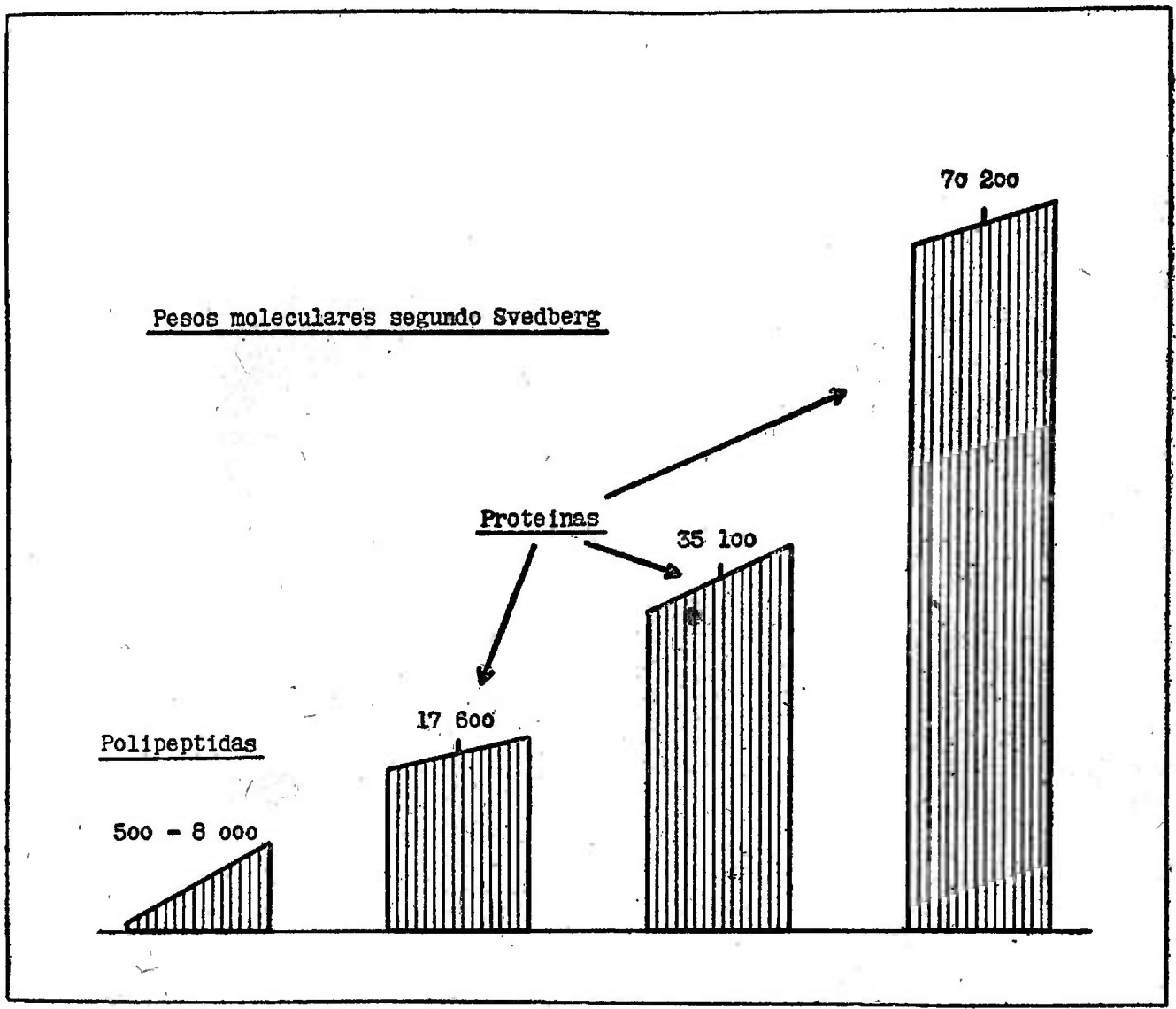

FIG. 1

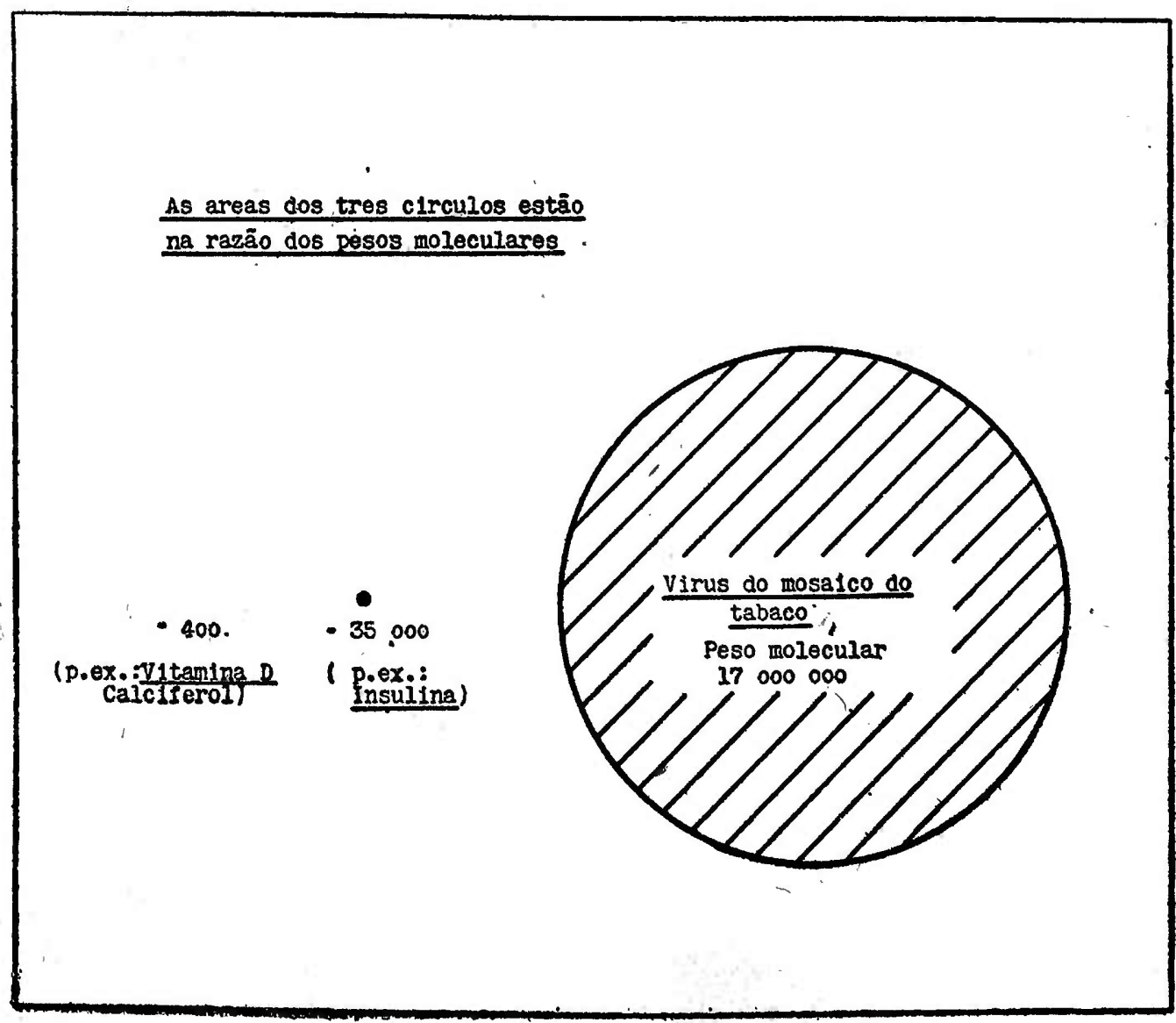

FIG. 2 
por mg. Obtem-se esta insulina extraindo-se glândulas pancreáticas frescas e moendo-as com alcool acidulado, concentrando o extrato por evaporação e continuando a purificar o resíduo por precipitação com sulfato de amônio(15). Abel tratava soluções diluidas de insulina amorfa com acetato de brucina, como "buffer" e obtinha cristais de insulina (16). Mais tarde verificou-se que, em lugar de brucina, tambem se podia usar saponina ou digitonina (17).

Ora, o químico sempre aceita sem discussão, que a forma cristalizada seja a forma mais pura de uma substância. No caso da insulina, tal a princípio não parecia suceder. Aindà me lembro claramente do espanto causado, quando a Dra. Dingemanse, de Amsterdam, no Congresso de Farmacologia de Wuerzburg, em 1928 nos comunicou seus resultados. Ela obtivera preparados amorfos de insulina, que seriam 4 vezes mais ativos que a insulina cristalizada ${ }^{(18)}$. Nos anos seguintes verificou-se, mediante exhaustivos esforços, que seu achado não passava de um engano muito perdoavel (19). A insulina cristalizada é realmente a forma mais pura e mais ativa de insulina. Encerra $22 \mathrm{U}$. F. por $\mathrm{mg}$.

Nos anos subsequentes, verificou-se que nem todos os preparados ámorfos de insulina cristalizam. A insulina do pâncreas de boi e dos orgãos insulares de alguns peixes cristalizam bem. A do pâncreas de porco cristaliza mal ou não cristaliza. Só em 1935 ScotT achou a razão provavel do fenômeno ${ }^{(20)}$. O pâncreas de porco não encerra zinco e para a cristalização da insulina é necessária uma pequena quantidade de zinco, ou de cobalto ou ainda de cádmio. No processo hoje empregado, deixa-se cristalizar insulina amorfa de uma solução muito diluida, tamponada, contendo cloreto de zinco. Obtem-se a insulina cristalizada com $90 \%$ de rendimento, e com $0,5 \%$ de zinco na molécula ${ }^{(21)}$.

Não é improvavel que a insulina cristalizada seja um sal de zinco, fixando por molécula 3 ions de zinco ${ }^{(20)}$. Não se pode tambem, recusar a hipótese de um sal de zinco cristalizar juntamente com a insulina (22). Os cristais proteicos em aparência totalmente unitários, raramente são isentos de moléculas menores incluidas. Só mediante o método da precipitação fracionada ${ }^{(23)}$, sedimentação no ultracentrifugador (12) e mediante eletroforese (24), se pode provar se um cristal proteico é realmente puro e isento de outras moléculas. Mas estes três métodos não são fáceis de manejar e ao determinarse em 1931, o peso molecular da insulina cristalizada por meio da ultracentrifugação ${ }^{(13)}$, o seu conteúdo em zinco nem se quer estava em discussão.

Só nos últimos anos, veio-se a d’ıvidar da pureza dos cristais proteicos, desdé que se descobriu que mesmo os mais lindos dessas grandes moléculas ainda continham inclusões. Quando em 1938, juntamente com Fraenkel-Conrat conseguí, no Instituto Butantã, a cristalização do princípio tóxico do veneno de cascavel ${ }^{(25)}$, durante muito tempo duvidei da pureza absoluta do corpo proteico que de- 
nominei crotoxima. Só depois que nós aquí, pelo método da precipitação ${ }^{(26)}$, THE SVEDBERG em Oslo por meio da ultracentrifugação ${ }^{(27)}$, e C. H. Li em San Francisco, por meio da eletroforese (28) demonstramos que não existem inclusões na crotoxina, acredito agora, que esta substância é realmente a primeira toxina proteica animal, perfeitamente pura e cristalizavel. Dados tão claros todavia, sobre a pureza dos cristais de insulina, não existem até agora.

Toda análise de insulina é dificultada, não só pelo seu teor em cinzas, aliás um tanto variavel' mas tambem pela água de cristalização, de muito dificil eliminação. Em ambiente seco, os cristais de insulina conteem $12 \%$ de água, que só são removidós no alto-vácuo com pentóxido de fósforo, depois de algum tempo ${ }^{(29)}$. Visto que para o esclarecimento da constituição da insulina os vários pesquisadores empregaram, nos últimos dez anos, insulinas de differentes proveniências com teores em cinzas diferentes e como talvez o material de análise muitas vezes não fora secado com suficiente energia, 'os resultados não são perfeitamente comparáveis. Parece-me provavel que os valores de carbono e nitrogênio em geral sejam achados um pouco baixo e os de hidrogênio, um pouco elevados. Certo é que o peso molẹcular da insulina. está por volta de $35.000^{(13)}$ até $40.000^{(20)}$, no máximo.

Por muito tempo se procurou responsabilizar um determinado grupo pela atividade da insulina. Todas estas tentativas falharam

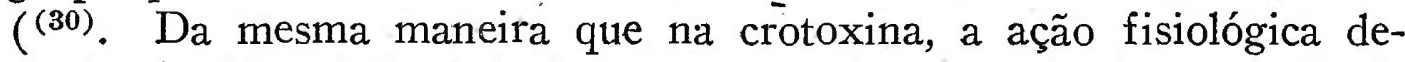
pende da disposição dos elementos proteicos constitutivos e não da presença de determinados componentes. Para o abaixamento do nivel glicêmico é necessária toda a grande molécula. Consoante este conceito, se destrói imediatamente a ação da insulina pela ação de fermentos. A pepsina por exemplo, dissolve simplesmente as ligações 'dos ácidos aminados, fazendo cessar a sua ação ${ }^{(31)}$.

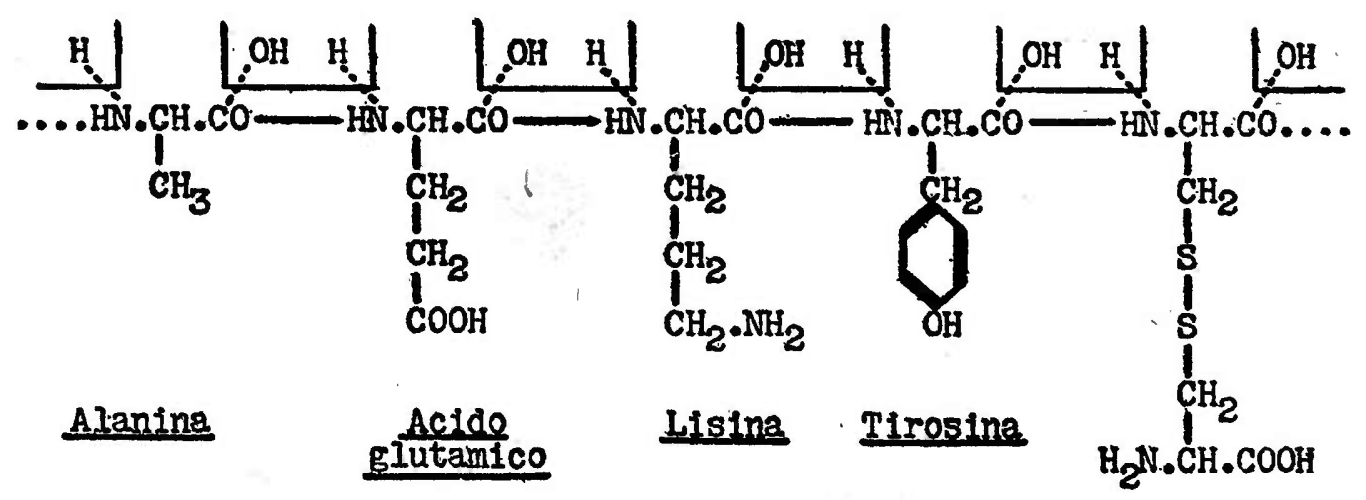

Esquema de uma parte de uma cadeia proteinica.

Cistina

FIG. 3

A grande questão é saber quais amino-ácidos e em que proporções, constituem a insulina. A leucina e o ácido glutamínico ${ }^{(32)}$ 
perfazem mais ou menos $60 \%$ e os outros $24 \%$ são formados por tirosina e cistina ${ }^{(33)}$. Isto chama a atenção, pois estes dois aminoácidos não são encontrados em nenhuma das outras substâncias proteicas solúveis em tão grande quantidade. Determinou-se qualitativamente na insulina, 5 outros ácidos aminados e procurou-se determina-los quantitativamente (34).

E enorme a dificuldade de determinar, com toda exatidão, a quantidade de cada âcido aminado, existente na insulina. Decompõe-se algumas gramas de insulina cristalizada de custo elevado com ácidos minerais fortes, mediante aquecimento prolongado. $\mathrm{Da}$ solução muito escura, retira-se os ácidos minerais e procura-se então, separar os ácidos aminados, extraordinariamente semelhantes entre si, com os mais aperfeiçoados métodos analíticos diretos e indiretos, preparativos e óticos. Isto entretanto, só foi possivel até um certo limite.

Maior confiança merecem, na minha opinião, as indicações de DU VIGNEAUD, no que respeita ao teôr em cistina (29). Este investigador utilizou uma insulina de fato completamente deshidratada e ơbteve mediante aquecimento com ácido chlorídrico-em ácido fórmico, hidrolisados inteiramente incolores. Verificou ele que todo o enxofre da insulina, salvo vestígios de metionina, se encontrava sob forma de cistina. Infelizmente em um hidrolisado assim preparado, não contendo produtos de decomposição, nunca foi verificado por métodos moderníssimos, a presença de outros ácidos aminados. Os dados fornecidos pelos melhores autores, sobre o teor de ácido glutaminico, variam entre $21 \%{ }^{(33)}$ e $30 \%{ }^{(32)}$.

O amino-ácido sulfurado cistina é particularmente interessante. Não há dúviđa que as pontes $-\mathrm{S}-\mathrm{S}$ - na insulina, da mesma forma que na crotoxina, são dotadas de importância especial em sua atividade. De acordo com determinadas reações de desintegração pareceu, durante algum tempo, que a cistina só estivesse encravada unilateralmente na insulina, como si o lado do grupo amino e carboxila estivesse livre ${ }^{(35)}$. Isto tornou a parecer duvidoso ${ }^{(36)}$ e àcredito que a cistina esteja na insulina - como tambem na crotoxina colocada de tal forma, que ambos os lados estejam ligados a outros ácidos aminados.

Naturalmente não só por decomposição, como tambem pelo emprego de toda sorte de reações químicas, se prócurou descobrir alguma coisa sobre a fórmula estrutural da insulina. Ela foi esterjficada (37), metilada ${ }^{(30)}$, acetilada ${ }^{(38)}$, tratada por ácido ${ }^{(29)}$ ou por alcali ${ }^{(30)}$. Tudo isto pouco nos adiantou no conhecimento de sua estrutura. Geralmente a molécula é inativada e não pode ser reativada. Interessantes sãó os ésteres inativos de insulina que, mediante saponificação, dão novamente insulina ativa.' Não tenho porem a impressão, de que caminhando nesta direção se possa adiantar muito e se possa provar experimentalmente como estão ligados os radicais entre st. 
Talvez aquí adiantem mais alguns raciocínios teóricos. 'M. BERGMANN estudou a periodicidade dos amino-ácidos nas proteinas e verificou que eles aperecem em números bem determinados ${ }^{(39)}$. Estes números previlegiados são produtos de potências de 2 e 3 . Tambem o curioso fato de grupos de substâncias proteicas sempre apresentarem o peso molecular._por volta de 17.600 ou 35.200 ou 70.400 assim se explica. É que as substâncias proteicas como a insulina e a crotoxina encerram $2^{5}$ vezes $3^{2}=288$ radicais aminoácidos.

Procurei combinar esta hipótese de Bergmann com os dados conhecidos experimentalmente sobre a constituição da insulina. Ora, si considerarmos como certo o número dogmático de Bergmann, 288 , o peso molecular da insulina por volta de 35.000 a 40.000 e o valor da cistina, sendo de $12,0 \%$ a $12,5 \%$, teremos 18 cistinas na insulina. Se a cistina estiver encaixada na fórmula como moléculá dupla, isto daria 36 meias cistinas. Para todos os demais radicais coloquei aproximadamente os valores em geral encontrados na literatura. Só no ácido glutamínico é que os valores divergem muito̊, mas já mencionei que tambem na literatura se registam grandes oscilaçôes. Provavelmente os valores do carbono e do nitrogênio foram achados muito baixos, e os do hidrogênio, demasiado altos. Segundo a minha especulação, a molécula de insulina terá cerca de 1.600 átomos de carbono, 2.400 de hidrogênio, 500 de oxigênio, 370 de nitrogênio e 36 de enxofre.

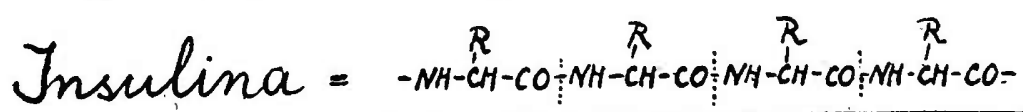

\begin{tabular}{|c|c|c|c|c|c|}
\hline numerro dos radicaus & $R=$ & & & slotta & outros. \\
\hline $2^{6} \times 3^{4} \cdot 96$ & \multirow{2}{*}{$\begin{array}{l}-\mathrm{CH}_{2}-\mathrm{CH}_{2}-\mathrm{COOH} \\
-\mathrm{CH}_{2}-\mathrm{CH}\left(\mathrm{CH}_{3}\right)_{2}\end{array}$} & \multicolumn{2}{|c|}{ acido glutaminico } & $39 \%$ & $27 \% ; 30 \%$ \\
\hline $2^{0} \times 3^{4}=81$ & & \multicolumn{2}{|c|}{ leucina } & $30 \%$ & $30 \%$ \\
\hline $2^{3} \times 3^{4}=24$ & $-\mathrm{CH}_{2}-\square \mathrm{OH}$ & \multicolumn{2}{|c|}{ tirosina } & $12 \%$ & $12 \%$ \\
\hline $2^{2} \times 3^{2}=36$ & $-\mathrm{CH}_{2}-\mathrm{S}-$ & \multicolumn{2}{|c|}{ cistina/z } & $12 \%$ & $12 \% ; 1250$ \\
\hline $2^{3} \times 3^{1} \cdot 24$ & $-\mathrm{CH}_{2} \rightleftharpoons \mathrm{NH}$ & \multicolumn{2}{|c|}{ histidina } & $12 \%$ & $8:$ \\
\hline $2^{3} \times 3^{0} \cdot 8$ & $-\mathrm{CH}_{2}-\mathrm{CH}_{2}-\mathrm{CH}_{2}-\mathrm{NH}-\mathrm{C}_{N}-\mathrm{NH}$ & \multicolumn{2}{|c|}{ anginina } & 48 & 38 \\
\hline $.8 .1-$ & $-\mathrm{CH}_{2}-\mathrm{CH}_{2}-\mathrm{CH}_{2}-\mathrm{CH}_{2}=\mathrm{NH} / 2$ & \multicolumn{2}{|c|}{ lisina } & $3 \%$ & 28 \\
\hline$: \quad \cdot 8$ & $-\mathrm{CH}_{2}-\mathrm{CH}_{2}-\mathrm{CH}_{2}-$ & \multirow{3}{*}{\multicolumn{2}{|c|}{$\begin{array}{l}\text { prolina } \\
\text { fenilalasina }\end{array}$}} & $3 \%$ & pouce \\
\hline $2^{0} \times 3^{1}=3$ & \multirow[t]{2}{*}{$-\mathrm{CH}_{2}-\square$} & & & $1 \%$ & - \\
\hline $2^{5} \times 3^{2}-288$ & & & & \multicolumn{2}{|l|}{1148} \\
\hline & H & $N$ & $s$ & $\begin{array}{c}\text { pesoo } \\
\text { modecube }\end{array}$ & $\left(\stackrel{N}{\left.N_{2}\right)}\right.$ \\
\hline calculado & $0.53,6 \%$ & 14,6 & 3,3 & 35900 & 11,2 \\
\hline achiado & $50,0 \%$ & 145 & 33 & $\begin{array}{l}35.100 \\
-10000\end{array}$ & 11,4 \\
\hline
\end{tabular}


Naturalmente não acredito que a composição por mim apresentada esteja certa. Ela só mostrará, como se deve imaginar, mais ou menos, a estrutura deste hormônio proteico. Faço questão de frizar quanto há ainda a investigar na insulina que já possuimos cristalina, há 16 anos. Pois, mesmo que saibamos com toda certeza se os meus números estão certos, ainda não sabemos se os vários radicais voltam regularmente, e como os vários amino-ácidos estão ligados. Nos últimos anos, por exemplo muito se discutiu uma teoria, segundo a qual os amino-ácidos na insulina não estariam ligados um ao outro na forma em cadeia indicada, mas assim de tal maneira que surgissem obrigatoriamente moléculas esféricas. ${ }^{(40)}$. Todas estas questões ainda estão em discussão.

Mas não só problemas químicos carecem ainda de solução na insulina. Antes que se desvendasse a estrutura da "insulina-velha" ("Alt-Insulin"), apareceram no mercado a. zinco-insulina, a protamino-insulina, a protamino-zinco-insulina e a "insulina nativa" ("Nativ-Insulin"). Estes produtos foram creados pelo mesmo motivo que levou ao emprego do benzoato de estradiol em logar do estradiol. Quer-se prolongar a ação do hormônio, retardando a sua absorção pelos humores orgânicos.

As quantidades mínimas de zinco, existentes na insulina cristalizada, não retardam a sua ação, embora tal às vezes se afirmasse de início. De modo diferente as coisas se passam nas verdadeiras zincoinsulinas. Há alguns anos foram feitas experiências clínicas com um preparado de insulina, contendo várias vezes tanto zinco quanto 0 peso sêco de insulina (41). Provavelmente, por ocasião de uma tal zinco-insulina ocorra uma modificação dos tecidos no ponto de injeção. E que os sais de zinco reagem como precipitantes fracos das proteinas. Dá-se assim uma absorção retardada da insulina. Todavia o preparado de zinco-insulina, com o tempo provoca fenômenos de irritação local, não se prestando portanto, para um emprego prolongado.

De outro raciocínio partiram os pesquisadores dinamarqueses, que crearam a protamina-insulina ${ }^{(42)}$. Eles procuraram mudar o ponto iso-elétrico da insulina, isto é, o ponto de sua menor solubilidade, situado mais ou menos no $\mathrm{pH}=5$, mais para o lado alcalino, quer dizer para o $\mathrm{pH}$ dos líquidos orgânicos. A insulina tem mais grupos ácidos do que básicos devendo portanto, ser dada em combinação com uma proteina fortemente básica, de preferência com a protamina monobásica do esperma do "Salmon". Mistura-se esta protamina a uma solução de insulina e se leva, pouco antes do uso ao $\mathrm{pH}$ do sangue. O precipitado fino que se forma, encerra praticamente toda a insulina. E injetado sob forma de suspensão. Como tempo de atividade, admite-se geralmente que a protaminoinsulina tenha 0 dobro do da insulina comum. ${ }^{(43)}$. As manifestações hipoglicêmicas são maị rarạs ${ }^{(44)}$ porque o organismo nessa 
forma de aplicação tem mais tempo para agir sobre a regulação glicêmica, que provavelmente se faz por intermédio da adrenalina.

Passou-se naturalmente a empregar o zinco e a protamina juntamente com a insulina. Surgiu assim, a protamina-zinco-insulina (45). Com relação a todas estas formas mais novas de insulina, ainda se formam juizos contraditórios, devendo ser colhidas novas experiências clínicas.

Em 1938/9 apareceu a notícia de que na Alemanha se isolara do pâncreas uma substância denominada insulina nativa ("NativInsulin") dotada de ação de depósito, sem adição de outras substâncias ${ }^{(46)}$. Segundo os escassos relatórios de que se dispõe, devese admitir que "insulina velha" ("Alt-Insulin") de até agora era um produto secundário de desintegração da insulina nativa, formado durante o processo de preparação. ${ }^{(47)}$. O ponto iso-elétrico da insulina nativa eștá perto de $\mathrm{pH}=7$. Importante é que dela se pode formar insulina cristalizada. Segundo os poucos trabalhos clínicos presentes, a insulina nativa representa mais um progresso na insulinoterapia. Cumpre esperar.

Uma coisa entretanto, é importante para a hormonologia: da mesma maneira que a tiroxina na tireoglobulina, assim parece que a insulina está encaixada na insulina nativa. É extranho com que facilidade estes grupos ativos de estrutura polipeptídica ou proteica podem ser separados de suas moléculas proteicas maiores, originais. E como se nestes corpos proteicos, o nosso conceito de combinação química, perdesse o seu sentido.

Talvez os senhores tenham aprendido alguma coisa das minhas explanações: ainda demora:á muito até que esteja perfeitamente desvendado o hormônio proteico de mais facil elaboração. É exatamente no problema da insuiina que se pode ver como é pouco o que sabemos até agora e saber isto, é importante para o verdadeiro cientista.

\section{BIBLIOGRAFIA}

(1) F. G. Banting, C. H. Best, J. B. Collip e coll. - Amer, Journ, of Physiology 62,162,559 (1922).

(2) E. A. Dorsy - Amer. Journ. of Physiol. 90,329 (1929).

(3) K. SiotTA, H. Ruschig e E. FELs - Berichte Dtsch. Chem. Gesellschaft

(4) E. LAQueur e coll. - Hoppe-Seylers Ztschr. physiol. Chemie 233,281 (1935).

(5) T. Reichstein e coll. - Nature 139,26 (1937).

(6) F. Stolz - Berichte Dtsch. Chem. Ges. 37,4149 (1904).

(7) C. R. Harington - Biochem. Journ. 20.293 (1926).

(8) F. BLUM - Klin. Wochschr. 10,231 (1931).

(9) Quart. Bull. Health. Organisation of League of Nations 4,526,641 (1935).

(10) JephCotT - Trans. Rov. Soc. Canada V Biol. Sci. 25,183 (1931).

(11) CHoay - Soc. Biol. 74,178 (1926); 109,1969 (1932).

(12) The Svedberg. Kolloid-Ztschr. 85,119 (1938).

(13) B. Sjögren e The Svedberg - Journ. Amer. Chem. Soc. 53,2657 (1931). 
(14) J. J. ABEL e E. M. K. G'EILING - Journ. Pharmacol. and Exper. Therapeut. 25,423 (1925).

(15) C. H. BEST - Handbuch der biol. Arbeitsmethoden V, parte 3 B, pag. 508 (1927).

(16) J. J. ABEL e coll. - Journ. Pharmacol. and exper. Therapeut. 31,55 (1927).

(17) C. R. 'Harington e D. A. Scott - Biochem. Journ. 23,384 (1929).

(18) E. Dingemanse - Verhandlg. der Dtsch. Pharmakol. Ges. 1928, pg. 44.

(19) A. M. Fischer e D. A. Scott - Trans. Roy. Soc. Canada V Biol. Sci. III, 28,75 (1934).

(20) D. A. Scott e A. M. Fischer - Biochem. Journ. 29,1048 (1935).

(21) D. A. Scott - Amer. Patent $2143590^{\circ}$ (1939).

(22) J. Eisenbrand e F. Wegel - Hoppe-Seylers Ztschr. physiol. Chemie 268,26 (1941).

(23) E. J. СонN - Physiol. Ref. 5,349 (1925).

(24) A. Trselius - Kolloid-Ztschr. 85,129 (1938).

(25) K. Slotta e H. L. Fraenkel-Conrat - Berichte Dtsch. Chemische Ges. 71,1076 (1938).

(26) K. Slotta e H. L. Fraenkel-Conrat - Memorias do Instituto Butantan XII,505 (1938).

(27) N. Gralén e The Svedberg - Biochem. Journ. 32,1375 (1938).

(28) C. H. LI - San Francisco, conforme experiencias até agora nãó publicadas.

(29) G. L. Miller e V. du Vigneaud - Journ. Biol. Chem. 118,101 (1937).

(30) H. Jensen e coll. - Journ. Chem. 114,199 (1936).

(31) K. FreudenberG e coll. - Hoppe-Seylers Ztschr. physiol Chemie 202,159 (1931).

(32) C. R. Harington e Hobson Mead - Biochem. Journ. 30,1598 (1936).

(33) H. Jensen e O. Wintersteiner - Journ. Biol. Chem. 98,281 (1932).

(34) H. Jensen e E. A. Evans - Journ. Biol. Chem. 108,1 (1935).

(35) K. Freudenberg - Technik Ind. Schweizer Chemiker Zeitung 1935,33.

(36) K. Freudenberg e TH. Wegmann - Hoppe-Seylers Ztschr. physiol. Chemie 233,159 (1935).

(37) A. F. Charles e D. A. Scott - Journ. Biol. Chem. 92,289 (1931).

(38) K. G. Stern e A. White - Journ. Biol. Chem. 122,371 (1938).

(39) M. Bergmann e K. Nifmann - Science 86,187 (1937).

(40) D. M. WRINCH - Science 88,148 (1938).

(41) L. A. Hulst e E. H. Vogelenzang - Nederl. Tijdschr. Geneeșk. 81,1916 (1937).

(42) H. C. Hagedorn e coll. - Journ. Amer. Med. Assoc. 106,177 (1936).

(43) D. A. SCOTT e A. M. Fischer - Journ. Pharmacol. 55,206 (1935).

(44) I. M. Rabinowitch e coll. - Canad. Med. Assoc. Journ. 35,124,239 (1936).

(45) B. SмIтн - California Med. 45,144 (1936).

(46) F. UMBER - Verhandlg. der Gesellschaft f. Verdauungskrankheiten, XIV. Tagung 1938,241.

(47) F. UMBer e coll. - Klin. Wochschr. 18,837 (1939). 


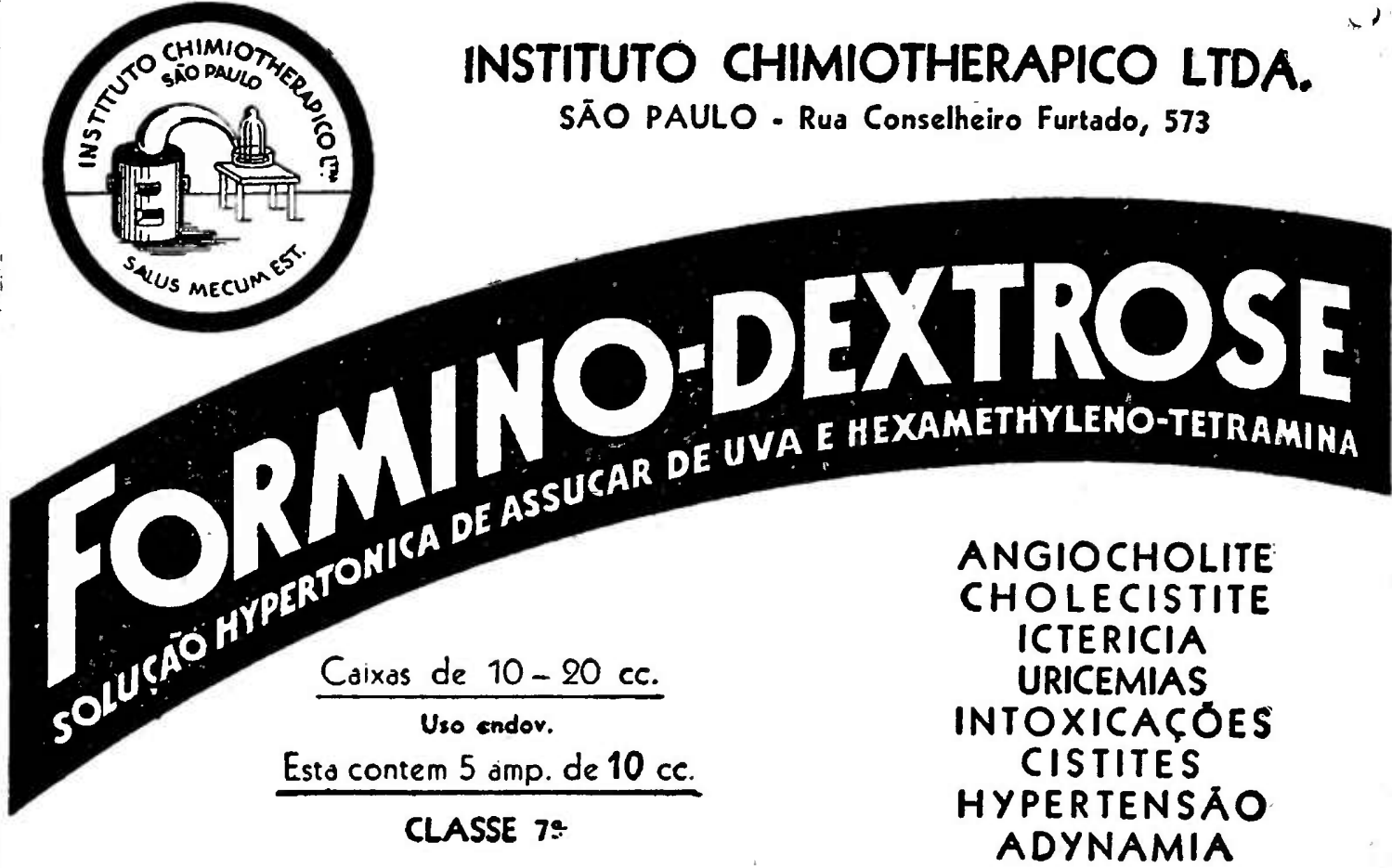

Approvado pelo D. N. S. P. Rio de Janeiro no. $596 \cdot 27.7 .936$

MAURELIO CHIORB OLI S. PAULO: R.RODRIGO SILYA, 24A RIO DE JANEIRO: R.DO CARMO,17

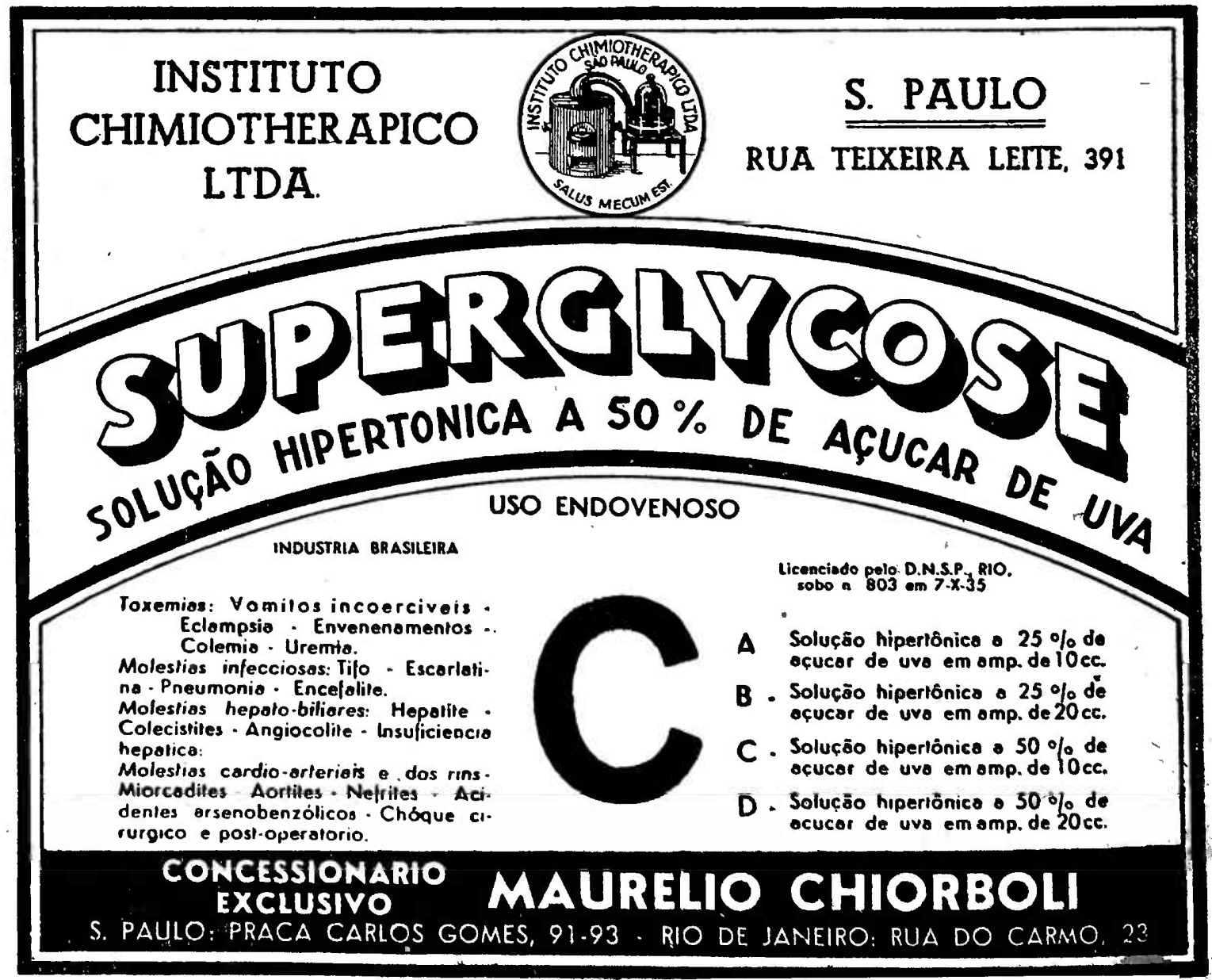

